\title{
KẾT QUẢ BƯớC ĐẦU ÁP DỤNG KỸ THUẬT ĐO BÃO HÒA OXY MÁU TĨNH MẠCH TRỘN ĐỄ THEO DÕI HUYẾT ĐộNG BỆNH NHÂN PHẪU THUẬT TIM CÓ NGUY CƠ CAO
}

\author{
Đoàn Đức Hoằng*, Bùi Đức Phú *, Huỳnh Văn Minh**
}

\section{Tóm tắt}

Trước nhu cầu triển khai và phát triển chương trình phẫu thuật tim ngày càng tăng tại các bệnh viện, điều quan trọng là các nhà hồi sức cần hiểu rõ các phương pháp theo dõi và hồi sức bệnh nhân sau mổ tim. Một trong những phương pháp hữu ích nhất và có lẽ chưa được nghiên cứu nhiều là kỹ thuật đo độ bão hòa oxy máu tĩnh mạch trộn $\left(\mathrm{S}_{\bar{v}} \mathrm{O}_{2}\right)$, cũng như mối tương quan giữa chỉ số này với chức năng tim, khả năng vận chuyển oxy cho mô $\left(\mathrm{DO}_{2}\right)$ và tiêu thụ oxy của cơ thể $\left(\mathrm{VO}_{2}\right)$.

Chúng tôi tiến hành nghiên cứu ngẫu nhiên trên 60 bệnh nhân được phẫu thuật tim với phác đồ hồi sức huyết động bao gồm bù dịch thích đáng và sử dụng inotrop nhằm mục đích đạt giá trị đích $\mathrm{S} \overline{\mathrm{V}} \mathrm{O}_{2} \geq 70 \%$ trong $8 \mathrm{~h}$ đầu sau mổ. Dobutamine sẽ được sử dụng cho đến liều $15 \mu \mathrm{g} / \mathrm{kg} /$ phút nếu như $\mathrm{S} \overline{\mathrm{O}} \mathrm{O}_{2}$ chưa đạt đích với liệu pháp bù dịch đơn thuần. Nhóm chứng được hồi sức tương tự nhưng theo mục đích đạt giá trị đích của áp lực động mạch phổi bít, chỉ số tim, huyết áp động mạch, và hematocrit. Giá trị $\mathrm{SV} \mathrm{O}_{2}$ là tương tự giữa 2 nhóm ở thời điểm ban đầu $(67 \pm 6 \%)$, nhưng có sự cải thiện tốt hơn giá trị này ở nhóm $\mathrm{SV} \mathrm{O}_{2}(69 \pm 5 \%$ ở nhóm chứng so với $71 \pm 4 \%$ ở nhóm $\left.\mathrm{SV}_{2} ; p<0,001\right)$. Hồi sức theo hướng dẫn $\mathrm{S} \square \mathrm{O}_{2}$ giúp cải thiện thời gian điều trị ở phòng hồi sức $(29,23 \pm 7,82$ vs. $40,27 \pm 9,04$ giờ; $p<0,001)$ và cải thiện các biến chứng sau mổ.

Hồi sức huyết động nhằm đạt giá trị đích $\mathrm{S} \square \mathrm{O}_{2}$ rất thích hợp trong bối cảnh bệnh nhân có nhiều nguyên nhân phức tạp gây giảm bão hòa oxy máu tĩnh mạch. Khuynh hướng theo dõi giá trị $\mathrm{S} \square \mathrm{O}_{2}$ như là một phương thức chuẩn để hồi sức các bệnh nhân sau phẫu thuật tim ngày nay.

\section{Abstract}

With more and more hospitals establishing and/or expanding their open-heart surgery programs, it is important for clinicians to have a clear understanding of the methods used for patient monitoring. One of the most versatile and probably most misunderstood, is mixed venous oxygen saturation $\left(\mathrm{SV}_{2}\right)$ and how it relates to cardiac function, oxygen delivery $\left(\mathrm{DO}_{2}\right)$ and oxygen consumption $\left(\mathrm{VO}_{2}\right)$.

\footnotetext{
* Bệnh viện Trung uoong Hué

** Truờng Đại hoc Y Dươc Huế
}

We randomized 60 patients undergoing elective cardiac surgery to a protocol involving the administration of intravenous fluid and inotropic therapy to attain a target $S \bar{v} \mathrm{O}_{2}$ of at least $70 \%$ in first $8 \mathrm{~h}$ after surgery. Dobutamine was administered in dose of up to $15 \mu \mathrm{g} / \mathrm{kg} / \mathrm{min}$ where the target $\mathrm{SV}_{\bar{v}}$ was not achieved with intravenous fluid alone. Control group patients were administered intravenous fluid and dobutamine to meet goals for pulmonary artery occlusion pressure, cardiac index, arterial pressure, and hematocrit. $\mathrm{S} \overline{\mathrm{V}} \mathrm{O}_{2}$ was similar in two groups at baseline $(67 \pm 6 \%)$, but there were greater improvements in $\mathrm{S} \overline{\mathrm{V}} \mathrm{O}_{2}$ in the $\mathrm{S} \overline{\mathrm{V}} \mathrm{O}_{2}$ group (control group $69 \pm 5 \%$ vs. $\quad \mathrm{SV}_{\bar{v}} \mathrm{O}_{2}$ group $71 \pm 4 \%$; $p<0,001) . \mathrm{S} \overline{\mathrm{V}} \mathrm{O}_{2}$ guided therapy was associated with a reduction in both ICU stay $(29,23 \pm 7,82$ vs. 40,27 \pm $9,04$ hours; $p<0,001)$ and the number of patients developing complications

Hemodynamic therapy to attain a target value for $\mathrm{SV}_{\overline{\mathrm{V}}} \mathrm{O}_{2}$ is more appropriate in this context as confounding causes of decreased venous saturation are minimized. This treatment is possible after cardiac surgery where postoperative intensive care admission is a standard of care.

\section{I. ĐẠT VẤN ĐỀ}

Các biến chứng sau phẫu thuật tim là nguyên nhân dẫn đến tử vong và được nhiều nhà hồi sức quan tâm. Nguyên nhân gây ra các biến chứng sau mổ là rất phức tạp, nhưng khả năng dự trữ tim - hô hấp kém dường như là yếu tố "chìa khóa" của vấn đề. Độ bão hòa oxy trong máu tĩnh mạch trộn $\left(\mathrm{SV} \mathrm{O}_{2}\right)$ là chỉ số phản ánh hiệu suất tim - hô hấp đặc biệt hữu ích giúp hướng dần can thiệp hồi sức bệnh nhân giai đoạn trong và sau mổ. Vì vậy, việc hiểu biết một cách tường tận về nguyên lý và sinh lý học của kỹ thuật đo lường oxy máu tĩnh mạch là mấu chốt để có được giải pháp hồi sức an toàn và hiệu quả trong thực hành lâm sàng. $\mathrm{S} \overline{\mathrm{O}_{2}}$ phản ánh cân bằng giữa khả năng vận chuyển oxy cho mô $\left(\mathrm{DO}_{2}\right)$ và tiêu thụ oxy của cơ thể $\left(\mathrm{VO}_{2}\right)$, và cân bằng này chịu tác động bởi rất nhiều các yếu tố ở giai đoạn trong và sau mồ. Chính vì vậy, chúng tôi muốn trình bày một kỹ thuật mới trong hồi sức huyết động về đo lường độ bão hòa oxy máu tĩnh mạch trộn và đánh giá kết quả ứng 
dụng này trên đối tượng các bệnh nhân phẫu thuật tim có nguy cơ cao.

\section{II. ĐỐI TƯỢ̂ VÀ PHƯƠNG PHÁP NGHIÊN CÚU}

Các bệnh nhân phẫu thuật tim có nguy cơ cao được theo dõi huyết động với ống thông Swan-Ganz và $\mathrm{SV} \mathrm{O}_{2}$ cũng như được hồi sức huyết động theo cùng một phác đồ bao gồm bù dịch thích hợp và sử dụng inotrop để đạt được mục đích hồi sức. Có 60 bệnh nhân chia làm 2 nhóm:

- Nhóm $\mathrm{SV} \mathrm{O}_{2}$ được hồi sức nhằm đạt giá trị đích $\mathrm{S}_{\bar{v}} \mathrm{O}_{2} \geq 70 \%$

- Nhóm chứng được hồi sức nhằm đạt các giá trị chuẩn của áp lực động mạch phổi bít, chỉ số tim, huyết áp động mạch và hematocrit

\title{
III. KẾT QUẢ NGHIÊN CÚU
}

\section{Đặc điểm chung của nhóm nghiên cứu}

- Tuổi trung bình là $40,8 \pm 15,8$. Nhómbệnh nhân trên 60 tuổi chiếm tỷ lệ cao và phân đều cho cả hai nhóm $(28,33 \%$ và $27,96 \% ; p>0,05)$

\section{Đặc điểm lâm sàng và cận lâm sàng}

- Đa sổ bệnh nhân có chẩn đoán bệnh lý van tim trong đó tổn thương nhiều van chiếm tỷ lệ cao 40\%, bệnh mạch vành chiếm $25 \%$.

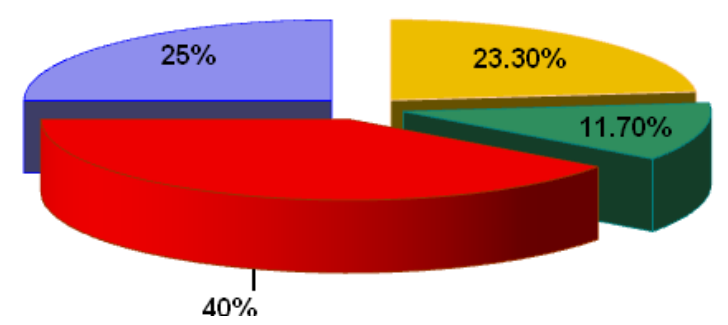

\author{
Van 2 lá \\ QVan động mạch chủ \\ Nhiều van \\ 口Vành
}

Biểu đồ 1 : phân bố chẩn đoán bệnh lý tim mạch trong nghiên cứu

Bảng 1: phân bố bệnh nhân theo NYHA

\begin{tabular}{lcccc}
\hline \multirow{2}{*}{ NYHA } & \multicolumn{2}{c}{ Nhóm $\mathrm{SV}_{2} \mathrm{O}_{2}$} & \multicolumn{2}{c}{ Nhóm chứng } \\
\hline I & $\mathrm{n}$ & $\%$ & 0 & $\%$ \\
II & 0 & 0 & 6 & 0 \\
III & 1 & 3,3 & 24 & 20,0 \\
IV & 20 & 66,7 & 0 & 00,0 \\
\hline
\end{tabular}

Tỷ lệ bệnh nhân có NYHA III là cao nhất ở cả 2 nhóm (66,7\% và $80 \%)$. Tỷ lệ bệnh nhân có NYHA IV nhóm $\mathrm{S} \overline{\mathrm{O}} \mathrm{O}_{2}$ là $30 \%$.

Bảng 2: phân bố bênh nhân theo phân suất tống máu (EF)

\begin{tabular}{lcccccc}
\hline & \multicolumn{3}{c}{$\mathrm{Sv}_{2}$} & \multicolumn{2}{c}{ Chứng } & \\
\cline { 2 - 5 } Phân suất tống máu (\%) & $\mathrm{n}$ & $\%$ & $\mathrm{n}$ & $\%$ & $\mathrm{p}$ \\
\hline$\geq 50 \%$ & 11 & 36,67 & 22 & 73,33 & 0,1015 \\
$<50 \%$ & 19 & 63,33 & 8 & 26,67 & 0,1644 \\
Tồng cộng & 30 & 100 & 30 & 100 & \\
EF trung bình $(\bar{X} \pm \mathrm{SD})$ & & & $49,98 \pm 8,39 \%$ & \\
\hline
\end{tabular}

Tỷ lệ bệnh nhân có $E F<50 \%$ chiếm tỉ lệ cao (63,33\% và 26,67\%; Sự khác biệt này không có ý nghĩa thống kê $(\mathrm{p}>0,05)$. 
Bảng 3: phân bố bênh nhân theo áp lực động mạch phổi tâm thu (PAP)

\begin{tabular}{lcccccc}
\hline & \multicolumn{3}{c}{$\mathrm{Sv}_{2}$} & \multicolumn{2}{c}{ Chứng } & \\
\cline { 2 - 5 } PAP $(\mathrm{mmHg})$ & $\mathrm{n}$ & $\%$ & $\mathrm{n}$ & $\%$ & $\mathrm{p}$ \\
$\mathrm{PAP}<50$ & 12 & 40 & 16 & 53,33 & 0,4450 \\
$\mathrm{PAP} \geq 50$ & 18 & 60 & 14 & 46,67 & 0,5296 \\
Tổng cộng & & & & & & \\
PAPS trung bình $(\bar{X} \pm \mathrm{SD})$ & & & & $53,33 \pm 20,56$ & \\
\hline
\end{tabular}

Bệnh nhân tăng áp phổi $\geq 50 \mathrm{mmHg}$ chiếm tỷ lệ cao ở cả 2 nhóm.

- Tỷ lệ bệnh nhân có thời gian $\mathrm{THNCT} \geq 120$ phút và/hoặc thời gian cặp $Đ M C \geq 90$ p ở nhóm $\mathrm{S} \mathrm{O}_{2}$ cao hơn ( $40 \%$ vs. $30 \%$, và $46,7 \%$ vs. $23,3 \%)$

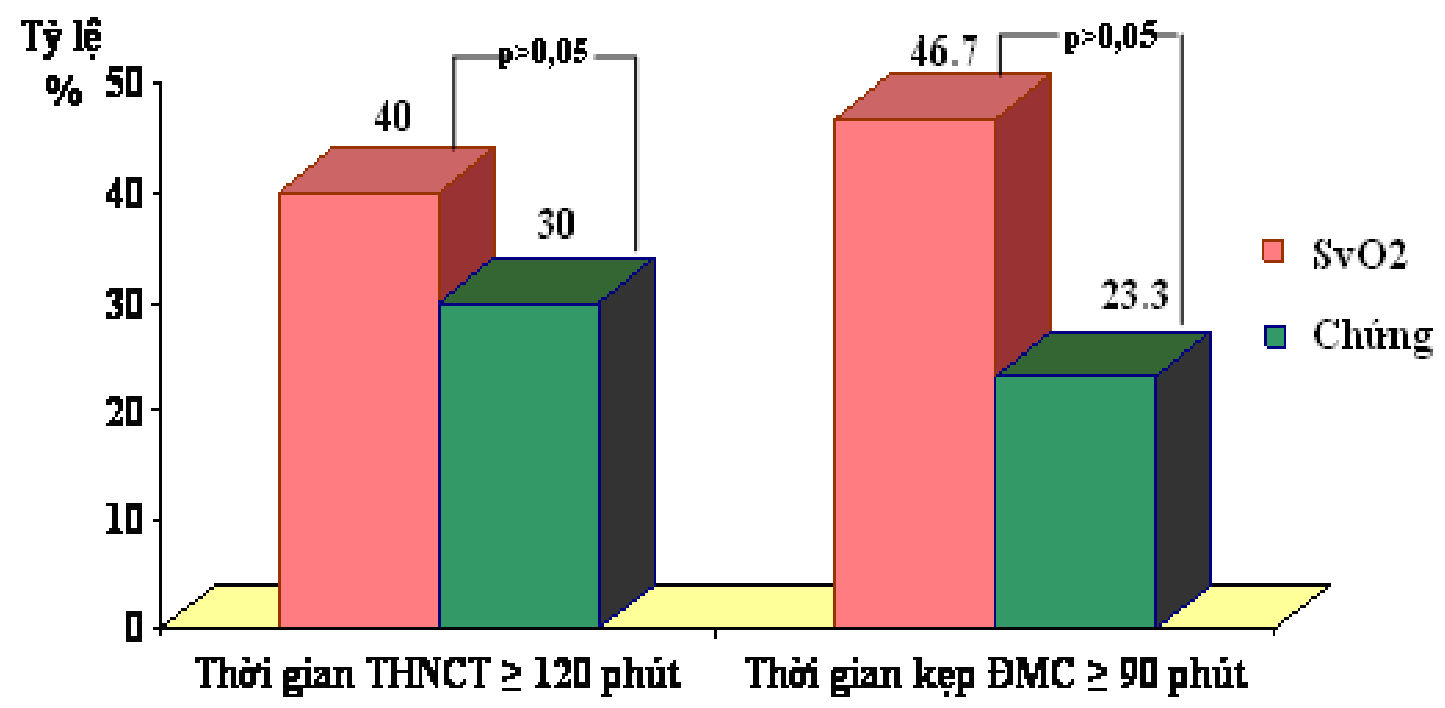

Biểu đồ 2: Phân bố bệnh nhân theo thời gian THNCT và cặp động mạch chủ

Đặc điểm các thông số đánh giá hồi sức huyết động

Bảng 4: giá trị trung bình hematocrit (Hct) trước và sau phẫu thuật

\begin{tabular}{llll}
\hline Thể tích huyết cầu $(\%)$ & $\mathrm{S} \square \mathrm{O}_{2}$ & Chứng & $\mathrm{p}$ \\
\hline Hct trước phẫu thuật $\left(\mathrm{T}_{0}\right)$ & $37,67 \pm 2,95$ & $39,46 \pm 3,69$ & 0,0637 \\
Hct sau phẫu thuật & $30,94 \pm 2,85$ & $29,79 \pm 2,60$ & 0,0897 \\
\hline
\end{tabular}

Giá trị trung bình hematocrit ở 2 nhóm tương đương nhau ở các thời điểm trước và sau phẫu thuật. Thể tích huyết cầu trung bình (Hct) sau phẫu thuật tim xấp xỉ 30\% ở cả hai nhóm nghiên cứu đảm bảo vận chuyển oxy cho mô. 
Bảng 5: giá trị trung bình của áp lực động mạch phổi bít PAWP và chỉ số tim CI (lít/phút/m²) ở các thời điểm trước mô $\left(\mathrm{t}_{0}\right)$ và $8 \mathrm{~h}\left(\mathrm{t}_{8}\right)$ sau mố

\begin{tabular}{llll}
\hline Thời điểm & Giá trị $\mathrm{S} \square \mathrm{O}_{2}$ & $\mathrm{p}$ \\
\hline \multirow{2}{*}{$\mathrm{t}_{0}$} & $\mathrm{PAWP}_{(1)}$ & $21,47 \pm 4,44$ & \\
& $\mathrm{IC}_{(\mathrm{a})}$ & $1,40 \pm 0,34$ & $\mathrm{p}_{(1)(2)}<0,001$ \\
& $\mathrm{pAWP}_{(\mathrm{a})(\mathrm{b})}<0,001$ \\
$\mathrm{t}_{8}$ & $\mathrm{IC}_{(\mathrm{b})}$ & $14,63 \pm 4,20$ & \\
\hline
\end{tabular}

Trước phẩu thuật, giá trị trung bình của áp lực động mạch phổi bít cao 21,47 mmHg; trong khi chỉ số tim rất thấp 1,40 lít $/ \mathrm{phút} / \mathrm{m}^{2}$. Giá trị này giảm sau phẩu thuật ở thời điểm $\mathrm{t}_{8}(14,63 \mathrm{mmHg})$. Chỉ số tim tăng lên sau phẩu thuật $\left(3,23\right.$ lít $/$ phút $/ \mathrm{m}^{2}$ ở thời điểm $\left.\mathrm{t}_{8}\right)$. $(\mathrm{p}<0,001)$.

Bảng 6: tương quan giữa chỉ số tim và $\operatorname{SvO}_{2}(\%),(n=30)$

\begin{tabular}{ll}
\hline $\mathrm{SvO}_{2}(\bar{X} \pm \mathrm{SD})$ & Chỉ số tim $(\bar{X} \pm \mathrm{SD})$ \\
\hline $73,49 \pm 4,55$ & $2,73 \pm 0,50$ \\
$\mathrm{r}=+0,41 ; \quad \mathrm{p}=0,0315$ & \\
\hline
\end{tabular}

Tương quan thuận khá chặt chẽ giữa chỉ số tim với $S \bar{v} \mathrm{O}_{2}(\mathrm{r}=+0,41 ; \mathrm{p}<0,05)$

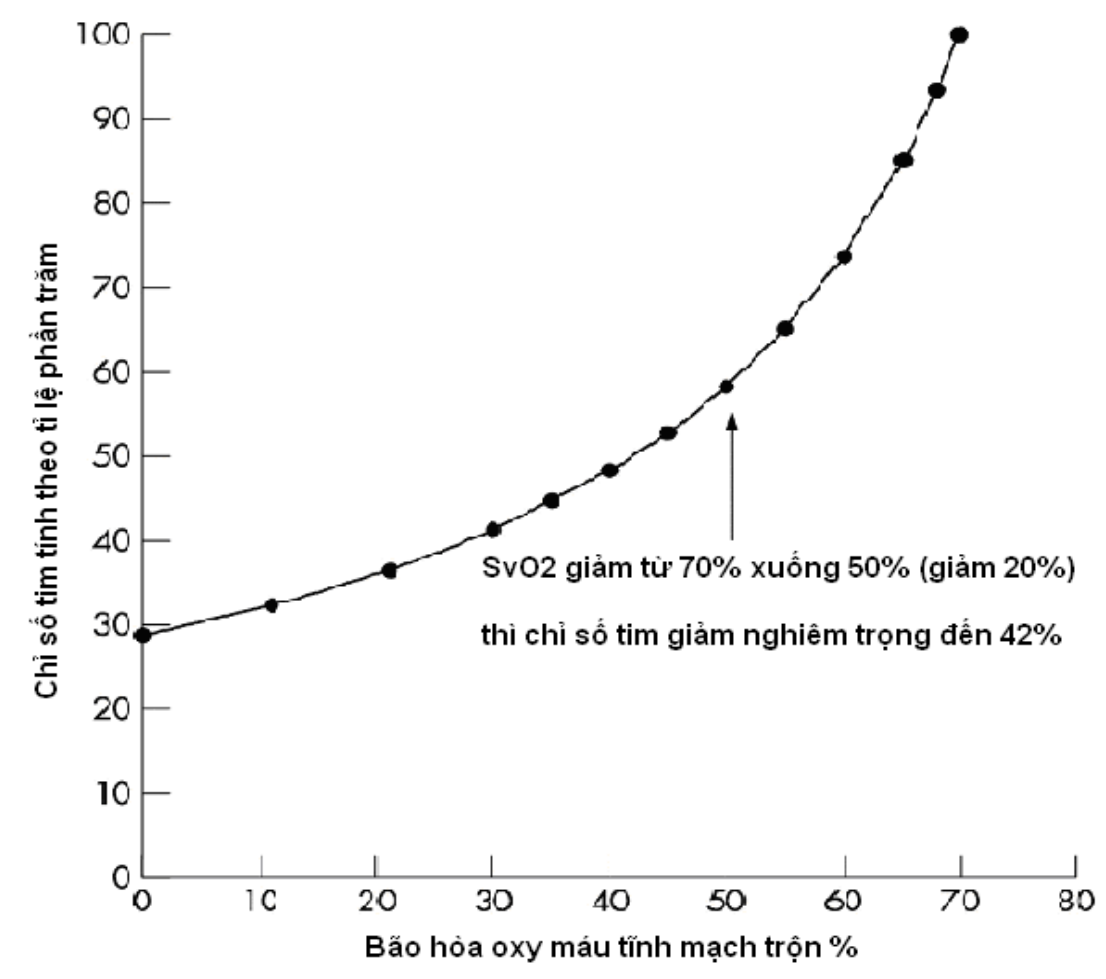

Biểu đồ 3: Tương quan giữa $\mathrm{SV}_{\mathrm{V}}$ và chỉ số tim 
Bảng 7: kết quả giá trị $\mathrm{S} \bar{v} \mathrm{O}_{2}$ ở thời điểm trước mổ $\left(\mathrm{t}_{0}\right)$ và $8 \mathrm{~h}$ sau mổ $\left(\mathrm{t}_{8}\right)$

\begin{tabular}{llll}
\hline Giá trị trung bình $\mathrm{S}_{\bar{v}} \mathrm{O}_{2}$ & Nhóm $\mathrm{S} \overline{\mathrm{V}} \mathrm{O}_{2}$ & Nhóm chứng & $\mathrm{p}$ \\
\hline Thời điểm $\mathrm{t}_{0}$ & $67 \pm 6 \%$ & & \\
Thời điểm $\mathrm{t}_{8}$ & $71 \pm 4 \%$ & $69 \pm 5 \%$ & $<0,001$ \\
\hline
\end{tabular}

Giá trị $\mathrm{S} \overline{\mathrm{O}} \mathrm{O}_{2}$ tương tự giữa 2 nhóm ở thời điểm trước mổ $(67 \pm 6 \%)$, sau đó cải thiện tốt hơn giá trị này ở nhóm $\mathrm{S} \overline{\mathrm{V}} \mathrm{O}_{2}(69 \pm 5 \%$ vs. $71 \pm 4 \% ; p<0,001)$.

Bảng 8: Giá trị $\mathrm{DO}_{2}$ thời điểm trước mổ $\left(\mathrm{t}_{0}\right)$ và $8 \mathrm{~h}$ sau mổ $\left(\mathrm{t}_{0}\right)\left(\mathrm{ml} / \mathrm{phút} . \mathrm{m}^{2}\right)$

\begin{tabular}{llll}
\hline Giá trị trung bình $\mathrm{DO}_{2}$ & Nhóm $\mathrm{S} \overline{\mathrm{v}} \mathrm{O}_{2}$ & Nhóm chứng & $\mathrm{p}$ \\
\hline Thời điểm $\mathrm{t}_{0}$ & $451 \pm 94$ & $446 \pm 99$ & $>0,05$ \\
Thời điểm $\mathrm{t}_{8}$ & $491 \pm 104$ & $696 \pm 111$ & $<0,001$ \\
\hline
\end{tabular}

Sự khác biệt khả năng vận chuyển oxy cho mô ở thời điểm $8 \mathrm{~h}$ đầu sau mổ, có sự cải thiện khả năng này ở nhóm $\mathrm{SV}_{\mathrm{V}} \mathrm{O}_{2}(\mathrm{p}<0,001)$.

Bảng 9: Giá trị VO thời điểm trước mổ $\left(\mathrm{t}_{0}\right)$ và $8 \mathrm{~h}$ sau mổ $\left(\mathrm{t}_{0}\right)\left(\mathrm{ml} / \mathrm{phút} . \mathrm{m}^{2}\right)$

\begin{tabular}{llll}
\hline Giá trị trung bình $\mathrm{VO}_{2}$ & Nhóm $\mathrm{SV}_{2}$ & Nhóm chứng & $\mathrm{p}$ \\
\hline Thời điểm $\mathrm{t}_{0}$ & $121 \pm 24$ & $120 \pm 25$ & $>0,05$ \\
Thời điểm $\mathrm{t}_{8}$ & $131 \pm 34$ & $206 \pm 35$ & $<0,001$ \\
\hline
\end{tabular}

Có sự cải thiện tiêu thu oxy giữa 2 nhóm bệnh nhân ở thời điểm thời điểm $8 \mathrm{~h}$ đầu sau mổ ở nhóm $\mathrm{S} \overline{\mathrm{V}} \mathrm{O}_{2}(\mathrm{p}<0,001)$.

- Thời gian thở máy trung bình rút ngắn ở nhóm $\mathrm{S}_{\bar{v}} \mathrm{O}_{2}(9,00 \pm 4,03$ so với $13,07 \pm 5,10$ giờ). Sự khác biệt có ý nghĩa thống kê ( $\mathrm{p}<0,001)$.

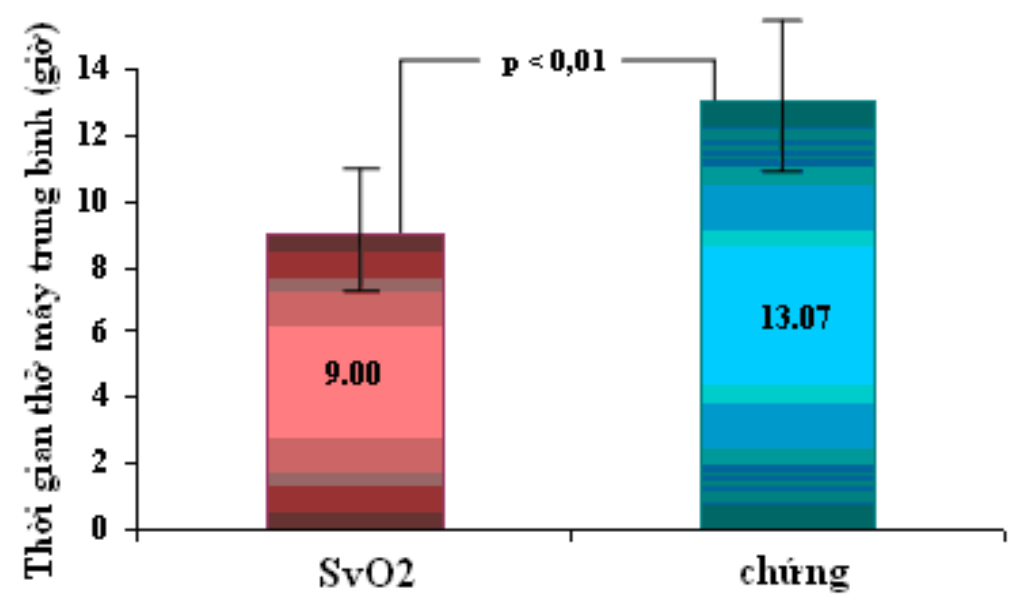

Biểu đồ 5 : Thời gian thở máy trung bình của 2 nhóm

- Thời gian trung bình điều trị tại hồi sức rút ngắn ở nhóm $\mathrm{SV}_{\mathrm{V}}(29,23 \pm 7,82$ vs. 40,27 \pm 9,04 giờ ; $\mathrm{p}<0,001)$. 


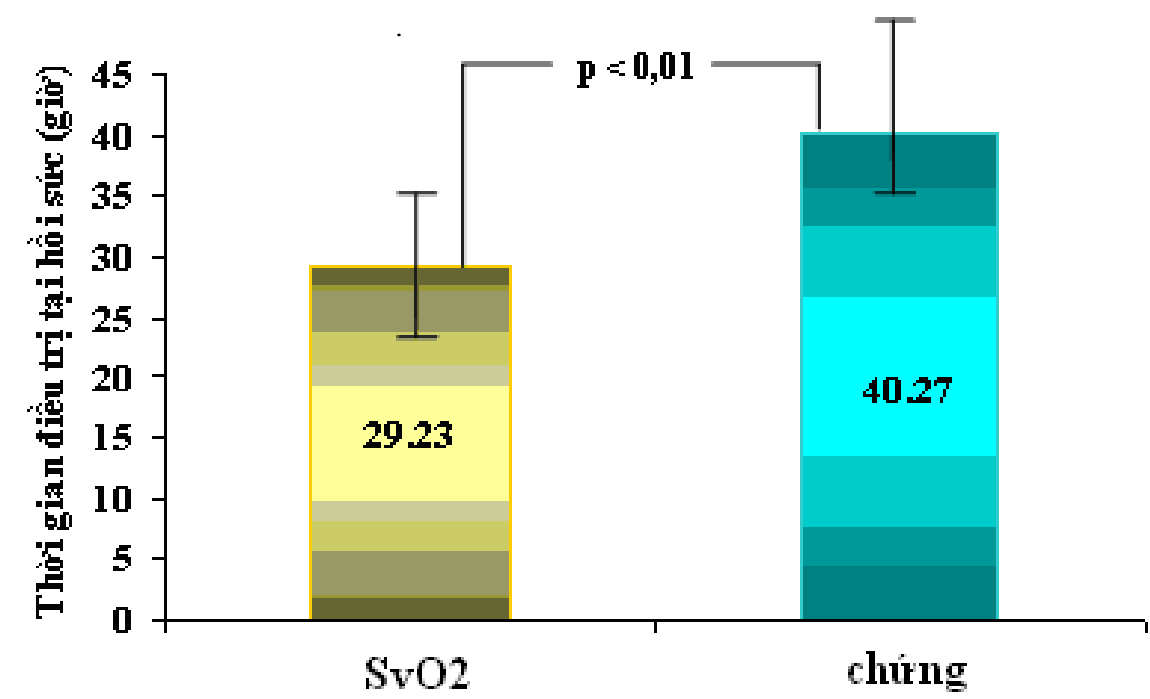

Biểu đồ 6: Thời gian trung bình điều trị tại hồi sức

Bảng 10: các biến chứng liên quan hồi sức huyết động sau mổ

\begin{tabular}{llll}
\hline Loại biến chứng & Nhóm $\mathrm{SV} \mathrm{O}_{2}$ & Nhóm chứng & $\mathrm{p}$ \\
\hline Suy tim cấp (ACC/AHA) & 2 & 0 & \\
Suy hô hấp & 4 & 1 & \\
Suy thận & 3 & 0 & $<0,01$ \\
Nhiễm trùng và sốc nhiễm trùng & 3 & 1 & \\
Chảy máu sau mổ & 2 & 2 & \\
Phù phổi & 2 & 0 & \\
Ngừng tim & 1 & 0 & \\
Số bệnh nhân có các biến chứng & $8(27 \%)$ & $3(10 \%)$ & \\
\hline
\end{tabular}

Tần suất xuất hiện các biến chứng liên quan hồi sức huyết động là đáng kể ở các bệnh nhân phẫu thuật tim có nguy cơ cao. Có sự khác biệt rõ rệt về tần suất của các biến chứng sau mổ giữa 2 nhóm. Tần suất này cải thiện đáng kể ở nhóm được hồi sức theo hướng dẫn $\mathrm{SV}_{2}$

\section{BÀN LUẬN}

Các bệnh nhân phẫu thuật tim có nguy cơ cao đều được sử dụng chung một phác đồ hồi sức huyết động [1] có monitoring tăng cường với catheter SwanGanz, và với các phương tiện hồi sức gồm liệu pháp bù dịch và inotrop. Chỉ sử dụng dobutamine khi huyết động vẫn chưa đạt các thông số đích khi đã bù dịch thích đáng. Các thông số huyêt động được đánh giá theo ESCAPE [3] với những mục đích hồi sức sau mổ tim giai đoạn sớm như sau

- Áp lực tĩnh mạch trung tâm : 8 - 12 mmHg điều chỉnh bằng bù dịch
- Huyết áp động mạch trung bình $>65 \mathrm{mmHg}$, dùng co mạch nếu cần

- Áp lực động mạch phổi bít : 12 - 18 mmHg, inotrop nếu cần

- Chỉ số tim $>2,5 \mathrm{ml} / \mathrm{phút} / \mathrm{m}^{2}$ : inotrop nếu cần,

- $\quad \mathrm{S} \overline{\mathrm{O}} \mathrm{O}_{2}>70 \%$ là mục đích có nhiều giá trị thực tiễn.

Nếu $\mathrm{S} \mathrm{O}_{2}<70 \%$, cần truyền thêm hồng cầu để đạt Hct $>30 \%$ và/hoặc sử dụng phối hợp dobutamine để tăng cải thiện chỉ số tim $\mathrm{CI}$ và khả năng vận chuyển oxy $\mathrm{DO}_{2}$. Hướng dẫn hồi sức huyết động theo $\mathrm{SV}_{\mathrm{V}} \mathrm{O}_{2}$ có thể được tóm tắt theo sơ đồ sau : 


\section{Sơ đồ: Hồi sức nhằm đạt huyết áp động mạch trung bình $>65 \mathrm{mmHg}$}

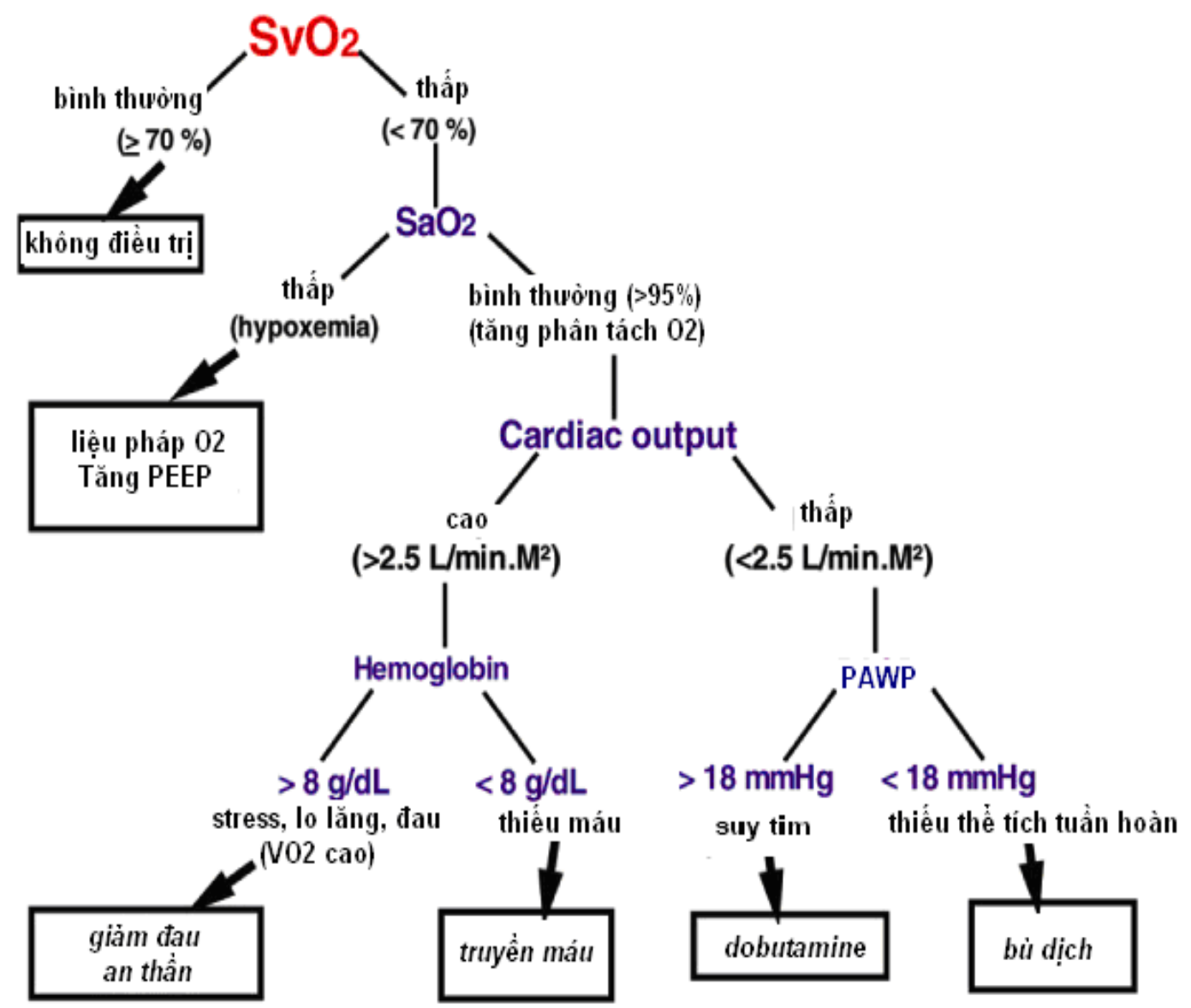

Các kết quả về lưu lượng tim hay chỉ số tim CI, độ bão hòa oxy máu tĩnh mạch trộn $\left(\mathrm{DO}_{2}\right)$, khả năng vận chuyển oxy cho mô $\left(\mathrm{DO}_{2}\right)$ và chỉ số tiêu thụ oxy của cơ thể $\left(\mathrm{VO}_{2}\right)$ có giá trị cao hơn hẳn ở nhóm $\mathrm{S} \mathrm{O}_{2}$ so với nhóm chứng (bảng $7,8,9$ ). Các giá trị $\mathrm{CI}$ và $\mathrm{DO}_{2}$ tăng cao hơn là hợp lý vì cho rằng có sự gia tăng bù chức năng tuần hoàn cần thiết trong trường hợp tăng chuyển hóa được phản ánh bởi tăng tiêu thụ oxy $\mathrm{VO}_{2}[2]$.

Kỹ thuật đo lường bão hòa oxy tĩnh mạch trộn $S \bar{v} \mathrm{O}_{2}$ giúp chẩn đoán nhanh chóng, phát hiện sớm các biến chứng hoặc các rối loạn mất bù sinh lý học xảy ra ở nhóm $\mathrm{S} \mathrm{O}_{2}$. Ngay từ trước mổ, trong mổ hoặc giai đoạn sớm sau mổ tim, giá trị $S \bar{V} \mathrm{O}_{2}$ giúp phát hiện sự mất bù tiềm ẩn ở các bệnh nhân có nguy co cao. Kết quả cho thấy các biến chứng liên quan đến hồi sức huyết động xảy ra tương đối ít và chỉ thoáng qua ở nhóm $\mathrm{S} \mathrm{O}_{2}$ (bảng 10).

- Theo dõi giá trị $S \overline{\mathrm{V}} \mathrm{O}_{2}$ đặc biệt thích hợp ở các bệnh nhân có rối loạn chức năng tim mạch vì đây là một thông số có tính nhạy cảm và tương quan rất chặt chẽ với chỉ số tim (bảng 6 và biểu đồ 3 ). Bão hòa oxy máu tĩnh mạch trộn là thông số phản ánh toàn bộ hiệu suất của hệ thống tim - hô hấp [4]. Một sự tụt giảm giá trị $\mathrm{S} \mathrm{O}_{2}$ khoảng $20 \%$ tương đương với giảm chỉ số tim khoảng $42 \%$ (biểu đồ 3 ). Giá trị $\mathrm{S}^{\mathrm{V}} \mathrm{O}_{2}$ giảm $10 \%$ là yếu tố gợi ý cần thiết phải có can thiệp trong vấn đề hồi sức huyết động.

Các thông số huyết áp, tần số tim, hematocrit, áp lực động mạch phổi bít, chỉ số tim ... vốn là những phương tiện đánh giá huyết động thường qui, nhưng đo lường $\mathrm{SV} \mathrm{O}_{2}$ đặc biệt có hiệu quả cao về cả kết quả lâm sàng và giá trị kinh tế trong mục đích điều trị cải thiện chức năng tuần hoàn sinh lý sau phẫu thuật tim. Nghiên cứu của Helmut F. Kaspar và cộng sự [5] đưa ra nhận xét theo dõi $\mathrm{SV} \mathrm{O}_{2}$ góp phần đạt được các mục đích hồi sức huyết động sớm hơn do đó cải thiện tần suất các biến chứng sau mổ cũng như rút ngắn thời gian thở máy và thời gian điều trị tăng cường ở phòng hồi sức. Kết quả này phù hợp với nghiên cứu của chúng tôi (biểu đồ 5,6 ) 


\section{KẾT LUẬN}

Các kết quả nghiên cứu chứng tỏ hiệu quả của kỹ thuật theo dõi bão hòa oxy tĩnh mạch trộn đặc biệt thích hợp để hồi sức huyết động bệnh nhân phẫu thuật tim có nguy cơ cao nhằm đạt mục đích cải thiện khả năng vận chuyển oxy cho mô để đáp ứng nhu cầu tiêu thụ oxy của cơ thể, cũng như để cải thiện tình trạng huyết động bệnh nhân ở giai đoạn sớm nhất. Chúng tôi tin rằng đối với những bệnh nhân có nguy cơ cao, việc theo dõi bão hòa oxy máu tĩnh mạch trộn $\mathrm{S} \mathrm{O}_{2}$ nên được thiết lập ngay từ trước mổ để có thể bắt đầu dự phòng cải thiện các thông số hiệu suất tim - hô hấp ngay từ trước mổ, và tiếp tục trong mổ và giai đoạn sớm sau mổ. Nghiên cứu tỏ ra có hiệu quả thuyết phục của một kỹ thuật theo dõi huyết động xâm nhập với các biến chứng và giá thành kinh tế là không đáng kể so với những cải thiện lâm sàng rất rõ nét trên những bệnh nhân trải qua những cuộc phẫu thuật lớn và có nguy cơ cao.

\section{TÀI LIẸU THAM KHẢO}

1. Eagle K. A., Brundage B. H., Chaitman, BR et al: "Guidelines for perioperative cardiovascular evaluation for cardiac surgery". Circulation 2009; 93: 1278 - 1317 and JACC 2009, 27: 910 - 948

2. Edward Lifesciences "Understanding continuous mixed venous oxygen saturation $\left(\mathrm{S} \square \mathrm{O}_{2}\right.$ ) monitoring with the Swan-Ganz oximetry TD System" $3^{\text {rd }}$ Edition 2011; $1161-11 / 00-$ CC.

3. ESCAPE Investigators and ESCAPE Study Coordinators: "Evaluation study of congestive heart failure and pulmonary artery catheterization effectiveness" 2010 the ESCAPE trial, Journal of American Medical Association, pp. 1625 - 1633.

4. Richard C., Monet X., Anguel N., Teboul J. L., : "Évaluation d'intérêt d'un outil de monitoring : le cathéter artériel pulmonaire". Insuffisance Circulatoire Aigue, (C) 2009 Elservier Masson SAS.

Shoemaker W. C., Appel P. L., Kram H. B., Waxman K. and Lee T. S. : "Prospective trial of supranormal values of survivors as therapeutic goals in high-risk surgical patients". Official publication of the American College of Chest physicians 2008; 1176- 1186. 